\title{
Political Cartoons as a Vehicle of Setting Social Agenda: The Newspaper Example
}

\author{
Iro Sani ${ }^{1}$, Mardziah Hayati Abdullah ${ }^{1}$, Faiz Sathi Abdullah ${ }^{1} \&$ Afida Mohamad Ali ${ }^{1}$ \\ ${ }^{1}$ Department of English, FBMK, UPM, Serdang, Malaysia \\ Correspondence: Iro Sani, PhD Candidate, Department of English, FBMK, UPM, Jalan 18/58, house no. 47A, \\ Taman Sri Serdang 43300, Selangor, Darul Ehsan, Malaysia. Tel: 60-17-284-1972. E-mail: isjibiya@yahoo.com
}

\author{
Received: January 16, $2012 \quad$ Accepted: February 16, $2012 \quad$ Published: May 1, 2012 \\ doi:10.5539/ass.v8n6p156 URL: http://dx.doi.org/10.5539/ass.v8n6p156
}

\begin{abstract}
In recent years, the cartoons genre has gained considerable research interest across disciplines; for example, communication, media studies and health sciences. More so, cartoons serve as potent source of data used to study social phenomena. This paper aims at illustrating how political cartoons are used as a vehicle of setting social agenda in Nigerian newspapers to reorient and shape the public opinion through recurrent depictions mirroring current socio-political issues at a given period. The cartoons texts were excerpted from two major Nigerian newspapers, Daily Trust and Vanguard during the period 2007-2010. One-hundred cartoons were selected using purposive sampling technique. Fifty cartoons were taken from each newspaper magazine. Specifically, content analysis was used to identify the themes contained in the cartoons depictions. Qualitative method was used to analyze the cartoons through semiotic analysis. The analysis is mainly concerned with the interpretation of the sign system based on the connotation and denotation elements in the cartoons. The results indicated that $80 \%$ of the themes focused on substantive issues through which social agenda is set to reflect social practices in the Nigerian social political contexts. Also, the results showed that Nigerian political cartoons set social agenda by mainly encapsulating current and sensitive issues that people are much concerned about. Finally, the study has identified the lack of supportive and clearly defined theoretical background in analyzing political cartoons as a major problem in previous cartoons research. Thus, this paper contributes to the cartoon research by offering theoretical insight to the cartoon genre through agenda setting theory of media effect.
\end{abstract}

Keywords: political cartoons, vehicle social agenda, media, genre, newspapers

\section{Introduction}

The purpose of this paper is to illustrate the role played by political cartoons in setting social agenda through highlighting topics and themes via the mass media and to identify and explain the meaning and importance of images or visual illustrations to depict issues and events as well as social representations of political figures, and prominent public officers in political cartoons published in the Nigerian prominent newspapers during the period 2007-2010. Specifically, two newspapers, Daily Trust and Vanguard were selected due to their wide readership. Similarly, understanding different approaches to language in its various links with media enables us to appreciate more on how language is used for communicative purposes which include information dissemination, a sense of mutual understanding and knowledge about social, economic, political and other related events that make up our social life in a society.

More specifically, media discourse harnesses language as an indispensable tool in media communication whereby journalists use both linguistic and nonlinguistic resources as devices, techniques or skills of manipulating language efficiently and persuasively to create effect and impression in a literary or dramatic work such as cartoons and to evoke a particular response from audience. These devices are employed purposely to communicate with the audience in order to persuade them towards perceiving a particular topic from a different point of view to make them more receptive and to provide rational argument for making public opinion that may bring positive changes in society.

Additionally, the paper demonstrates how political cartoons are ingeniously used to setting social agenda in Nigerian media discourse especially newspaper cartoons. Cartoons constitute one of the most strategic and vital medium of using language to disseminate information and reorient the public on current issues reflecting social 
realities of a particular society at a particular time. Given the use of linguistic and nonlinguistic devices, the political cartoon genre provides a medium for communicating messages through which social and political agenda are set. El Refaie (2009) illustrates that Political cartoons, function as communicative tools in society. They form a distinctive media genre with its own history, specific styles, conventions and communicative purposes. Cartoon as a media message, is an illustration done usually on a single panel and published on the editorial or comment pages of a newspaper or magazine. In essence, the paper illustrates a better understanding of the role of political cartoons in setting social agenda and also demonstrates how political cartoons are used to construct reality of issues and represent social representations of politicians and prominent individuals in a given society. Hence, it provides an inspiration for further research.

\section{Literature Review}

Previous studies on political cartoons have focused on their nature and functions. For instance, Streicher, (1965, as cited in Benoit, Klyukovski, McHale, \& Airne, 2001) examined the communicative function of political cartoons where they explored the influence of political cartoons on public opinion concerning Clinton-Lewinsky-Starr affair about the impeachment trial proceedings of President Clinton.; Morrison (1969) investigated the unique features of political cartoons; Medhurst and DeSousa (1981) focused on the rhetorical form of political cartoons; Wigston (2002) conducted a case study on Aids and Political Cartoons, where he examined the role of political cartoons in Aids struggle in South Africa; Cahn (1984) studied political cartoons as tools for communication; Bivins (1984; (Bormann, Koester, \& Bennett, 1978) concentrated mainly on content analysis of political cartoons; Baldry and Thibault (2006) focused on political cartoons and public representation; while Handl (1990) examined political cartoons in Australian newspapers and identified the central themes which represented the typical Australian citizens and the political parties.

Another group of studies looked at the visual power of political cartoons in reflecting social and political issues in society. For example, Morris (1992) explored the power of political cartoons in the democratic process; also Morris (1993) studied visual rhetorics employed in political cartoons using a structuralist approach. Delporte (1995) examined satirical cartoons ridiculing the Dreyfus affair during the period 1894-1906; likewise, Feldman (1995) studied the contents of editorial cartoons and analyzed the symbolic themes on the depictions of six Japanese prime ministers. Edwards (1997) analyzed political cartoons depictions of the 1988 presidential campaign in terms of image, metaphor and narrative; and Seymour-Ure (2001) focused on the future of political cartoons in British where he predicted that the cartoons will continue to flourish in future. Olaniyan (1997) investigated on cartooning traditions in Nigerian media print. On the use of visual rhetoric, Refaie (2003) examined the use of visual metaphors in political cartoons in Australian newspapers. Conners (2007) investigated on political cartoons and the popular culture in the 2004 presidential campaign in US.

In terms of how political cartoons depict social representations, Edwards and Ware (2005) focused on how political cartoons represent public opinions in campaign media. More specifically, (Han, 2006) focused on political satire, where he examined the Japanese Cartoon Journalism and its pictorial statements on Korea. Similarly, Najjar (2007) explored political cartoons as essential sites for constructing Palestinian Refugee identity. From African perspectives, Eko (2007) investigated on how some African newspapers dehumanized and deterritorialized four African leaders. Also from Nigerian context, Udoaka (2003) investigated on the perceptions of audiences on Nigeria political cartoons. In terms of depicting a particular ideological point of view, Mazid (2008) explored political and ideological representations in Bush and bin Laden's cartoons depictions. Reflecting on political commentary Townsend, McDonald, and Esders (2008) examined how political cartoons illustrated Australia's work choices debate on civil service policies. El Refaie (2009) conducted a research on Multiliteracies and political cartoons interpretation. In one of his recent studies, El Refaie and Hörschelmann, 2010) explored young peoples' responses to political cartoons. Willems (2011) examined satirical depictions of Zimbabwean president to portray the political climate of the country. Significantly, the review of literature demonstrates that although there has been considerable research done on political cartoons, but little research has focused on how political cartoons are used as a vehicle of setting agenda especially in the Nigerian socio-political context. The findings of the study serve as answers to the research questions.

\section{Methodology}

To address the research questions guiding the study, the source of data has been obtained from the Nigerian newspapers that specifically publish political cartoons. The study uses qualitative paradigm through the use of semiotic analysis to analyze the political cartoons. The analysis is based on the interpretation of the sign system drawing on the connotation and denotations elements of the cartoons texts. Thus, the cartoon text was used as the 
core unit of analysis to investigate how cartoons are used to set social agenda in Nigerian political climate. Content analysis was used to sort out cartoon contents into topical themes reflecting current issues and events. Thus, content analysis is an essential instrument for studying and analyzing media contents and other related graphic or visual texts specifically cartoons. Specifically, agenda setting theory was used to provide theoretical background of the cartoons depictions covering sensitive issues in the Nigerian socio-political context.

The sample comprises $100(\mathrm{~N}=100)$ cartoons texts extracted from two most prominent Nigerian newspapers and one magazine namely: Vanguard and Daily Trust and Tell magazine. The cartoons were extracted during the period 2010. Daily Trust cartoons comprise 45 cartoons $(n=45)$ of the samples followed by Vanguard with 45 $(\mathrm{n}=45)$ and Tell with $10(\mathrm{n}=10)$ respectively. One thing remarkable about the period at which the cartoons were extracted was that it was seen as a rigorous period full of political activities prior to the general elections in 2011. For the purpose of illustration five cartoons were specifically selected and analyzed in the paper. Interestingly, the thematic structure form substantive issues reflecting the Nigerian socio-political context.

In order to ensure reliability, Cohen's Kappa method for calculating inter-observer agreement is used. To establish Cohen's Kappa, we need to calculate the proportion of agreement between the two coders by dividing the total number of agreement by the total number of tallies. Therefore, the required Cohen's kappa $(\mathrm{k})$ is $\mathbf{0 . 9 1}$. The level of agreement is considered excellent when it falls within the range $\mathbf{0 . 7 5}$ and above. Hence, the level of agreement in this case is excellent which shows that the results of this method indicate an intercorder reliability of 0.91. These provide the procedures upon which Nigerian political cartoons were categorized. For the purpose of illustration, Table 1 presents substantive issues of the Nigerian political cartoons. (Refer to the appendix section)

Table 1. Presents frequency distribution of themes in Nigerian political cartoons

\begin{tabular}{lllllll}
\hline Substantive Themes & \multicolumn{2}{c}{ Daily Trust } & Vanguard & & \multicolumn{2}{c}{ Tell } \\
\cline { 2 - 7 } & Freq. & Percent & Freq. & Percent & Freq. & Percent \\
& & & & & & \\
\hline Democratic Governance & $\mathbf{8}$ & $\mathbf{2 0}$ & 7 & 17.5 & $\mathbf{6}$ & $\mathbf{3 0}$ \\
Corruption & 5 & 12.5 & $\mathbf{8}$ & $\mathbf{2 0}$ & 4 & 20 \\
Economy & 7 & 17.5 & 5 & 12.5 & 5 & 25 \\
Living Standard & 6 & 15 & 4 & 10 & 2 & 10 \\
Security & 4 & 10 & 1 & 2.5 & 0 & 0 \\
Foreign Policy & 2 & 5 & 2 & 5 & 2 & 10 \\
\hline Total & 32 & $80 \%$ & 27 & $67.5 \%$ & 19 & $95 \%$ \\
\hline 3.1 & & & & &
\end{tabular}

\subsection{Theoretical Backgrounds}

The paper uses agenda setting theory (McCombs \& Shaw, 1972), to provide theoretical insight on how political cartoons are used to depict topical issues in newspapers as a strategy of setting social agenda to reorient and shape public opinion especially in Nigerian socio-political context. Agenda Setting Theory is one of the Media Effect Theories related to this study that accounts for the relationship between the media and the public. It also explains the way media function towards information dissemination in a society through different genres such as news, cartoons, advertisements etc. Agenda-setting Theory is a media effect theory developed by Maxwell McCombs and Donald Shaw in 1972. The theory emanated from their prominent study on the role of the media in 1968. Thus, it provides an explanation on the existing relationship between the extent at which media give coverage to a particular story and the level of importance people attach to such a story. Therefore, media reflect upon the news worthiness of stories in framing public agendas. Agenda setting theory provides clear explanation on the contrivable nature of media contents that appeal to the intellects of the public by calling their considerable attention to issues and events in a society through intermittent coverage of such issues and events in different media channels.

Additionally, agenda setting operates at two levels, first and second level of agenda setting. The first level focuses on the objects of transmission; for instance, politicians, political parties, events and public officers; the mass media informs the public what to think about through their coverage. The second level focuses on how the public about the objects by highlighting their attributes (Carroll \& McCombs, 2003). 


\subsection{Research Questions}

Two research questions were formulated to guide the conduct of the study. They are aimed at addressing the following questions:

1) How are political cartoons used to set social agenda in the Nigerian context?

2) What are the predominant themes of Nigerian political cartoons during the period 2007-2010?

The analysis addresses the research questions leading to the findings of the study.

\section{Analysis}

The analysis is aimed at addressing research questions informing the study. Table 1 presents the frequency and percentage of topical issues of Nigerian political cartoons. These issues reflected crucial and current socio-political issues in Nigeria at the moment. The media through recurrent depictions of the cartoons reflecting the reality of what is currently happening construct social agenda. The emergent themes of the cartoons fall under two main categories namely: substantive and nonsubstantive themes.

\subsection{Substantive Contents of Political Cartoons}

Table 4 indicates that Daily Trust newspaper depicted more substantive themes, representing $80 \%$ of cartoons samples extracted from the newspaper compared to nonsubstantive themes that comprise $20 \%$ of the samples. Moreover, six themes emerged under substantive category which includes: Democratic governance, Corruption, Economy, Living Standards, Security, and Foreign Policy. From these themes, 'Democratic Governance emerged as the most frequent theme with $20 \%$ of the total samples from the newspaper. However, the least frequent theme is foreign relations with only 2 depictions representing $5 \%$.

On the other hand, Vanguard newspaper also focused more on substantive themes but in lesser degree compared to Daily Trust, where the themes comprised $67.5 \%$ of the total samples from Vanguard newspaper. Interestingly, 'Corruption is the most frequent theme having the highest percentage of $20 \%$. Here the two newspapers differ in terms of issue they gave preference to despite the fact that they focused more on substantive theme than nonsubstantive.

With the exception of one depiction on 'Electoral practices' representing 5\%, Tell magazine contrastingly did not prioritize nonsubstantive themes in its cartoons. Thus, tell magazine portrayed the highest percentage of substantive themes with $95 \%$ of the total samples from the magazine more than the newspapers. However, the magazine converged with Daily Trust by depicting 'Democratic Leadership with highest frequency.

Figure 1 refers to president Goodluck, who is depicted ostentatiously in a mood of self reflection. He was standing in front of an enormous dressing mirror smiling too widely in admiration of his mirror image, living behind his briefcase. He was specifically amazed with his bulging stomach by holding it with both hands as a sign of affluence. The point of reflection was his sudden rise from the post of a lecturer to an incumbent president. Immediately behind him is a terribly emaciated beggar with cross sign on his head, carrying a big begging bowl. The beggar, wearing worn-out dresses tagged "masses" spreading his hand to beg for sustenance, but the president appears completely oblivious about him.

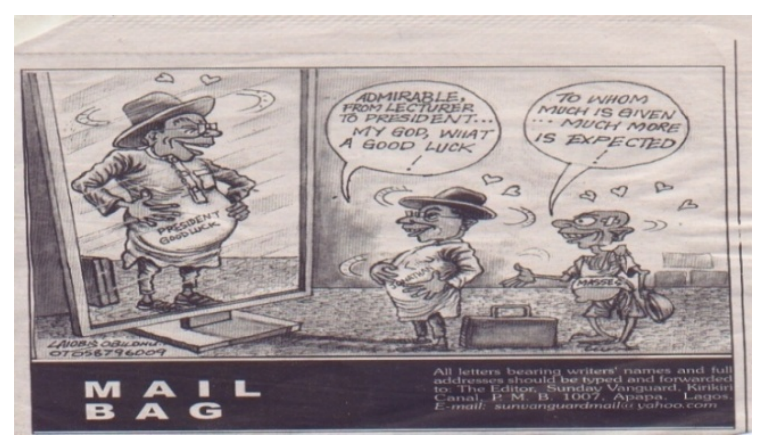

Figure 1. Depicts democratic leadership, Vanguard, July 20, 2010

The cartoon connotatively highlights Nigerian major obstacle which is democratic problem where sybaritic political leaders live in luxuriously high living condition at the detriment of their followers who have been subjected to abject poverty and destitution. The cartoon draws people attention to address this problem of bad governance in Nigeria.

Figure 2 portrays corruption in the public sector which is more detrimental to the survival and development of any nation. Connotatively the depiction portrays a typical nature of Nigerian public officers where public offices 
are turned into something else like a dining room. The displayed cup, saucer and teaspoon have turned an official writing desk into tea table and this indicate how public facilities are personalized which is an act of appropriation. Similarly, the obese nature of the two officers reveals that they live above their legitimate earnings.

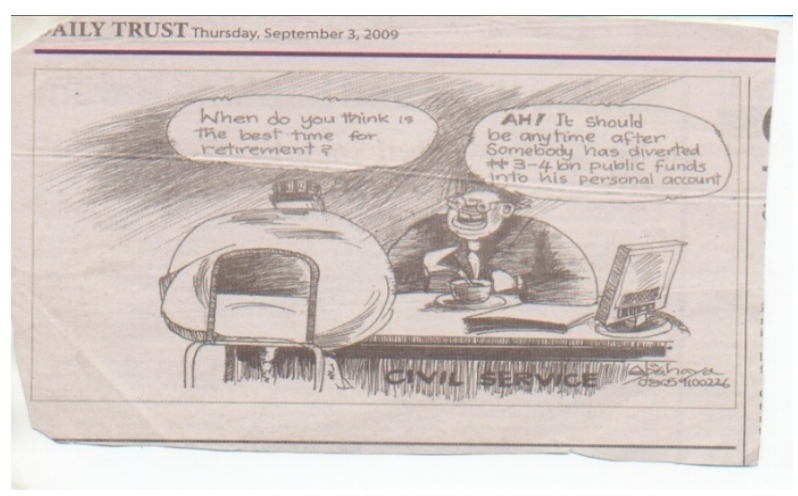

Figure 2. Depicts corruption Daily Trust, September 3, 2009

Denotatively, this cartoon (Figure 3) represents Nigerian annual deficit budget and the manner at which it is presented. The cartoon comments on poor implementation of the budgeting system. Ideally, a budget is done at the beginning of each fiscal year usually in January but the reverse is the case where budget is passed almost towards the end of the year in November or December as shown on both cards.

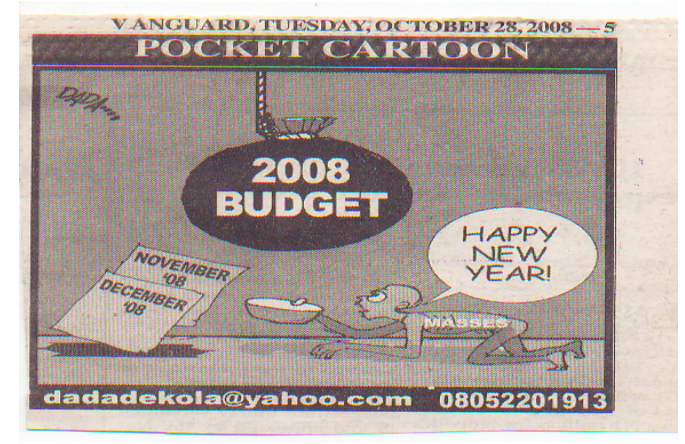

Figure 3. Depicts Nigerian economy, Vanguard, May 2, 2009

Connotatively, the cartoon has demonstrated how budget is unnecessarily delayed in Nigeria which is a clear sign of economic instability resulting from bad leadership. In fact the container is a sign that symbolizes the nation's economy. Moreover, budget is a parameter that determines the strength and weakness of a nation's economy. From the depiction, the budget fails to cater for basic needs of ordinary people who are masses and the majority of Nigerian citizens. The beggar represents the living standard of the ordinary people who are impoverished by harsh and unfavorable economic policies.

Figure 4 highlights peoples' responses towards electricity failure related to Nigeria's current power supply and its incapacitation towards generating and distributing electricity in the entire country.

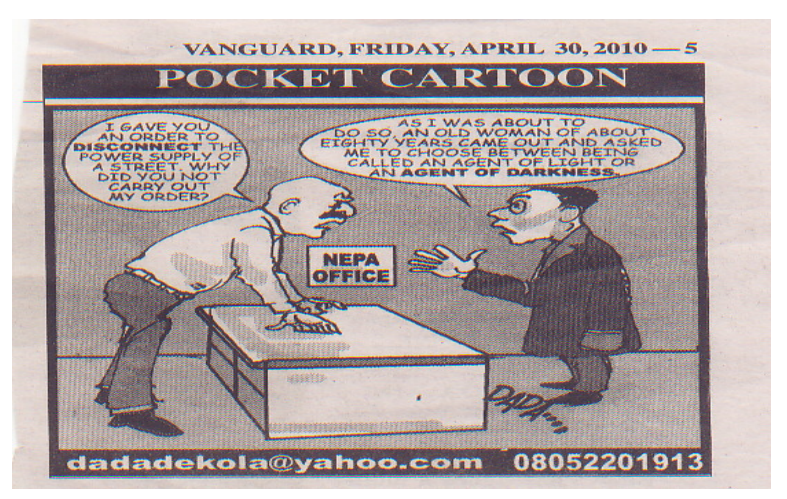

Figure 4. Depicts Nigerian infrastructure, Vanguard, September 12, 2008 
This cartoon illustrates more on how power supply in Nigeria is deteriorating. Nigerian citizens got used to several hours of darkness. The cartoon denotatively refers to "NEPA" officials in one of their offices. The acronym NEPA, stands for "National Electric Power Authority", which is a government owned company responsible for generating and distributing electricity in Nigeria and some neighboring countries such as Niger Republic. The connotation of the cartoon signifies that Nigerian people experience incessant power failure every so often over a long period. Therefore, the acute shortage of electricity in the cartoon reflects the current infrastructural problems as an indicator of the people's living standard in Nigeria.

Figure 5 depicts the act of kidnapping people especially foreign workers from oil companies and other prominent individuals in Niger Delta area as another heinous crime related to the theme of insecurity. The rate at which people are continuously kidnapped inflicts fear and sense of insecurity to people.

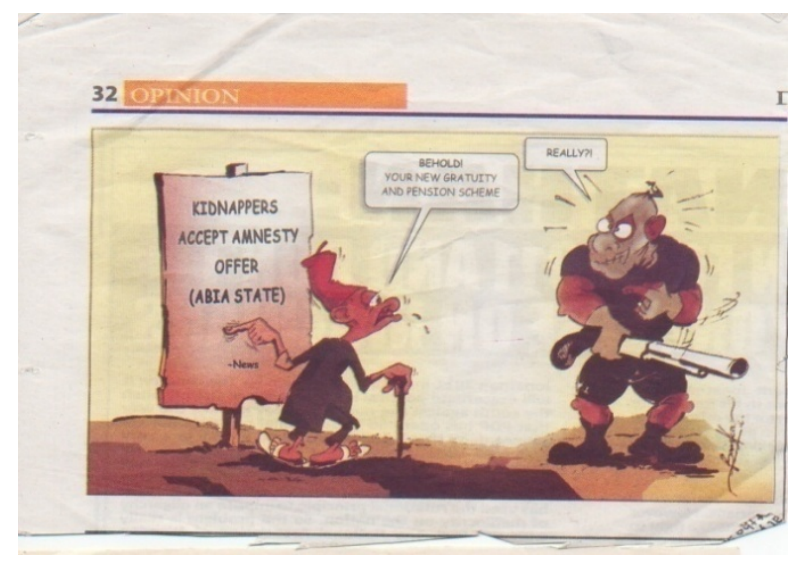

Figure 5. Depicts insecurity in Nigeria, Daily Trust, March 9, 2009

In this cartoon, Figure 5, a picture of a giant terrorist carrying a sophisticated gun is depicted wearing what looks more like a mask than eye glasses. He appears to be in full readiness to attack anybody that crosses his boundaries. On the far side, stands a billboard containing breaking news over the amnesty offer to the kidnappers by Abia state in Niger Delta region. On the other side an old man representing poor masses points to the board interpreting the message as a new form of gratuity and pension given to the kidnappers. Connotatively, the cartoon clearly expresses insensitiveness of current political leaders in handling sensitive issues of high magnitude. Because crime of this nature requires severe punishment to serve as deterrent to others who may likely commit same mistake.

The denotation of this cartoon (Figure 6) refers to the late president depicted on transit carrying a huge container full of cooked food labeled "Democracy" heading to Niger republic as indicated by the signboard. On the far side is a pictorial image of a pauper who fell flat on the bare ground, holding an empty begging bowl with one hand and the national flag with the other hand. The pauper was looking keenly at the food. Furthermore, he is implicitly begging for the food by his body gesture, though not sure whether he will get his share. The president is aware of the pauper's condition but assured him that he has to serve his neighbor first.

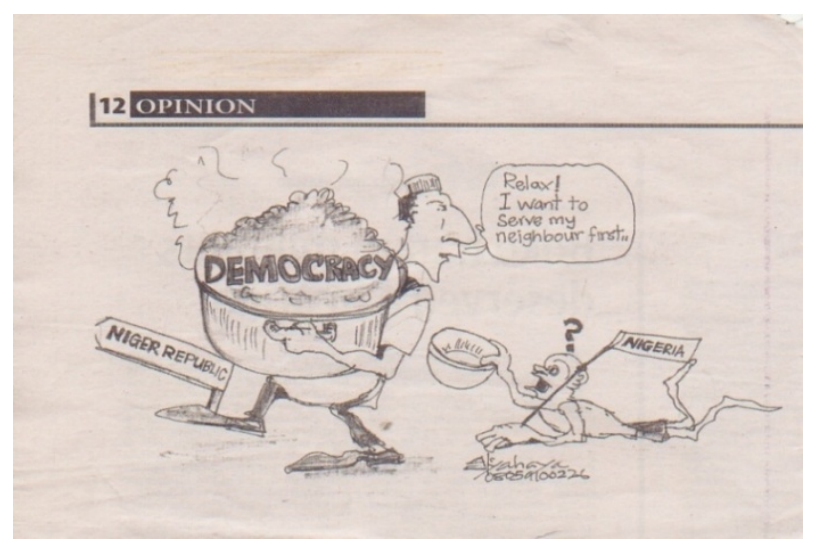

Figure 6. Ddepicts foreign policy, Daily Trust, December 23, 2007 
Connotatively, the cartoon addresses the current foreign policy in Nigerian whereby leaders give much more preference to foreign aid than attending to the needs of their people. They become oblivious to the people's basic needs. Undeniably, food is one of the most basic necessities of life to human beings. The pauper depicted in the cartoon represents the impoverished condition of the masses in Nigeria.

In contrast, only $20 \%$ of the sample portrayed nonsubstantive issues. Furthermore, nonsubstantive issues focus more on depicting behaviors and characteristics of politicians and electoral issues. Perhaps this could be attributed to the fact that the issues under this thematic category are not as sensitive and crucial to people as substantive issues that people are so much concerned about. Agenda setting is much concerned about what people concerned with and think about at a given time.

\section{Findings}

The findings of the study demonstrate how cartoons are used in media discourse to social agenda. Through political cartoons, the media comment on current socio-political issues in order to transform people and keep them informed and abreast of topical issues that affect their lives. Additionally, the cartoons illustrate how agenda is set by focusing on specific issues of interest at a particular moment through recurrent and wide coverage of such issues. Obviously, the role of media in setting agenda is much significant in reorienting the people pertaining to relevant issues that are so important to the public interest. Through agenda setting, the media influence what people are much concerned and pay attention to. Therefore the media attach relevance to importance of issues through wide coverage thereby giving it popularity and constitute useful debates that shape peoples understanding over such issues as a step forward in solving societal problems. The agenda setting theory has provided useful explanation on what shape the media agenda and the influence of media on the public.

To address the first research question that focuses on how political cartoons are used to set agenda, Table 1 presents the cartoons thematic structure which comprises pertinent issues to people and society at a given moment. Thus, identifying a specific thematic structure determines the communicative function of the cartoons in a given medium. Therefore, to determine how cartoons set agenda, there must be a pattern that indicates the cartoons thematic structure. Interestingly, the study found out that Nigerian political cartoons adopt a specific pattern of depicting substantive issues reflecting current socio-political issues in the Nigerian context. These substantive issues constitute $80 \%$ of the total cartoons sample.

The second research question focuses on the predominant themes that emerged from the cartoons depictions. Interestingly, six themes emerged from the depictions which cartoons texts encapsulated in recurrent coverage as a way of setting agenda through which worthiness and prominence of issues and events are portrayed to the public. The themes are considered to be substantive because they reflect topical and sensitive issues of national interest which people are much concerned and worry about. Hence, they constitute social agenda of the moment. These themes are: Democratic leadership which focuses on good governance as an urgent need that people are aspiring for. Corruption is the next theme which deals with dishonesty, fraud or financial scandal especially among political leaders and prominent public officers. Next theme is economy which focuses on how the nation's resources are managed to cater for the well being of its people and to avoid extravagance or mismanagement of such resources. Living standard is another theme that deals with people's welfare in relation to basic, obtainable and available infrastructures. The available infrastructures determine people's living standard. Security is also a theme that focuses on the level or state of safety in the nation and protection against attack within or outside its territory. The last theme is foreign policy which refers to depictions that characterize international relation or how a country relates to other countries or those who reside outside the country. Absolutely, these topical issues were encapsulated in the Nigerian political cartoons to set social agenda which is aimed at initiating social and political reforms in a given society.

\section{Conclusion}

So far, this paper has demonstrated how cartoons are used to accomplish communicative tasks in Nigerian print media and how the cartoons are creatively used to set agenda thereby providing political commentary and debate in witty and artful fashion through which social realities are mirrored in the nation's wider socio-political arena. Therefore, the study has shown that the cartoon genre constitutes a formidable medium of communication through which the media set social agenda by attaching relevance to importance of issues and events through recurrent coverage aimed at shaping the people's understanding of the issues to bring positive change in society. Thus, Nigerian political cartoons serve as agent of setting social agenda used by the media specifically to build up public attention, reorient people and initiate social and political reforms in Nigeria. However, this paper posits that the political cartoons constitute a potent multimodal genre comprising linguistic and nonlinguistic devices to convey meaningful messages; this requires more theoretical input to make the genre more comprehensible to the 
reading public. One major problem encountered in analyzing political cartoons is attributed to the lack of definite supportive theories (Wigstont, 2002). This paper specifically contributes to the cartoon research by offering theoretical insight through the use of agenda setting theory to provide a better understanding of how political cartoons are used to depict important issues in society.

Generally, political cartoons genre contributes to the understanding of media representation of issues, people and events. The genre also offers a useful source of data for studying media and public discourses. Hence, it is a potent and interesting research area of understanding social relationships and experiences. For this reason, there is a need for further research to determine the effect of political cartoons in initiating social and political reforms in society. Given that the cartoons are communicative and social artifacts, future studies should also focus on the feasibility of political cartoons towards understanding a particular social phenomenon and how they can be harnessed to build and shape public opinion.

\section{References}

Baldry, \& Thibault, A., P.J. (2006). Multimedia Toolkit and Coursebook. London: Equinox.

Benoit, W. L., Klyukovski, A., McHale, J., \& Airne, D. (2001). A fantasy theme analysis of political cartoons on the Clinton-Lewinsky-Starr affair. Critical Studies in Media Communication, 18(4), 377-394. http://dx.doi.org/10.1080/07393180128097

Bivins. (1984). Format preferences in editorial cartooning. Journalism Quarterly, 63, 182-185.

Bormann, E. G., Koester, J., \& Bennett, J. (1978). Political cartoons and salient rhetorical fantasies: An empirical analysis of the'76 presidential campaign. Communication Monographs, 45(4), 317-329. http://dx.doi.org/10.1080/03637757809375977

Cahn, D. (1984). The political cartoon as communication. Media Development, 4, 39-42.

Carroll, C. E., \& McCombs, M. (2003). Agenda-setting effects of business news on the public's images and opinions about major corporations. Corporate Reputation Review, 6(1), 36-46. http://dx.doi.org/10.1057/palgrave.crr.1540188

Conners, J. L. (2007). Popular culture in political cartoons: Analyzing cartoonist approaches. PS: Political Science \& Politics, 40(02), 261-265. http://dx.doi.org/10.1017/S1049096507070400

Delporte, C. (1995). Images of French-French war: caricature at a time of Dreyfus affair. French cultural studies, 6(2), 221-248.

Edwards, J. L. (1997). Political cartoons in the 1988 presidential campaign: Image, metaphor, and narrative. Routledge.

Edwards, J. L., \& Ware, L. (2005). Representing the Public in Campaign Media. American Behavioral Scientist, 49(3), 466. http://dx.doi.org/10.1177/0002764205279416

Eko, L. (2007). It's a Political Jungle Out There. International Communication Gazette, 69(3), 219. http://dx.doi.org/10.1177/1748048507076577

El Refaie, E. (2009). Multiliteracies: how readers interpret political cartoons. Visual Communication, 8(2), 181. http://dx.doi.org/10.1177/1470357209102113

El Refaie, E., \& Hörschelmann, K. (2010). Young people's readings of a political cartoon and the concept of multimodal literacy. Discourse: Studies in the Cultural Politics of Education, 31(2), 195-207. http://dx.doi.org/10.1080/01596301003679719

Feldman, O. (1995). Political reality and editorial cartoons in Japan: how the national dailies illustrate the japanese Prime Minister. Journalism Quarterly, 72, 571-571. http://dx.doi.org/10.1177/107769909507200308

Han, J. S. (2006). Empire of Comic Visions: Japanese Cartoon Journalism and its Pictorial Statements on Korea, 1876-1910. Japanese Studies, 26(3), 283-302. http://dx.doi.org/10.1080/10371390600986637

Handl, H. (1990). Streotypication in mass media: The case of political caricature in Australian daily newspapers. Angewandte-sozialforschung, 16(1-2), 101-107.

Mazid, B. E. (2008). Cowboy and misanthrope: a critical (discourse) analysis of Bush and bin Laden cartoons. Discourse \& Communication, 2(4), 433.

McCombs, M. E., \& Shaw, D. L. (1972). The agenda-setting function of mass media. Public opinion quarterly, 36(2), 176. http://dx.doi.org/10.1086/267990 
Medhurst, M. J., \& DeSousa, M. A. (1981). Political cartoons as rhetorical forms: A taxonomy of graphic discourse. Communication Monographs.

Morris, R. (1992). Cartoons and the political system: Canada, Quebec, Wales, and England. Canadian journal of communication, 17(2).

Morris, R. (1993). Visual rhetoric in political cartoons: A structuralist approach. Metaphor and Symbol, 8(3), 195-210. http://dx.doi.org/10.1207/s15327868ms0803_5

Morrison, M. C. (1969). The role of the political cartoonist in image making. Communication Studies, 20(4), 252-260.

Najjar, O. A. (2007). Cartoons as a Site for the Construction of Palestinian Refugee Identity. Journal of Communication Inquiry, 31(3), 255. http://dx.doi.org/10.1177/0196859907302455

Olaniyan, T. (1997). The traditions of CARTOONING in Nigeria. Glendora Review: African Quarterly on the Arts, 2(2).

Refaie, E. E. (2003). Understanding visual metaphor: The example of newspaper cartoons. Visual Communication, 2(1), 75. http://dx.doi.org/10.1177/1470357203002001755

Seymour-Ure, C. (2001). What Future for the British Political Cartoon? Journalism Studies, 2(3), 333-355. http://dx.doi.org/10.1080/14616700120062202

Townsend, K. J., McDonald, P., \& Esders, L. (2008). How Political, satirical cartoons illustrate Australia's WorkChoices debate. Australian Review of Public Affairs, 9(1), 1-26.

Udoaka, N. (2003). UYO RESIDENTS'PERCEPTION OF POLITICAL CARTOONS IN NIGERIAN NEWSPAPERS. Nsukka journal of history, 270.

Wigston, D. (2002). Aids and political cartoons: a case study.

Willems, W. (2011). Comic Strips and "the Crisis": Postcolonial Laughter and Coping With Everyday Life in Zimbabwe. Popular Communication, 9(2), 126-145. http://dx.doi.org/10.1080/15405702.2011.562099 